\title{
Highly catalytic oxidative desulfurization and denitrogenation of diesel using anchored- silica-gel vanadium-substituted Dawson-type polyoxometalate
}

\author{
F. Banisharif ${ }^{1,2,}$, M.R. Dehghani ${ }^{1}$, M.C. Capel-Sanchez ${ }^{2}$, J.M. Campos-Martin ${ }^{2}$ \\ ${ }^{1}$ School of Chemical Engineering, Iran University of Science and Technology, Narmak, \\ Tehran, Iran \\ ${ }^{2}$ Grupo de Energía y Química Sostenibles (EQS) Instituto de Catálisis y Petroleoquímica, \\ CSIC. Marie Curie, 2 Cantoblanco, 28049 Madrid, Spain
}

\begin{abstract}
The aim of this article is to study the extractive-catalytic oxidative desulfurization (ECODS) of the model oil containing several model S-containing compounds as well as N-containing compound using a heterogeneous vanadium substituted Dawson-type polyoxometalate catalyst under atmospheric pressure and temperature lower than $100{ }^{\circ} \mathrm{C}$. The catalyst was prepared by ion exchange with alkyl ammonium derivatives covalently anchored to silica gel. The potential of this methodology was illustrated by oxidation of $100 \%$ quinoline and $80 \%$ of total sulfur in model oil containing 500 ppmw sulfur and $70 \%$ of total sulfur in model oil 1500 ppmw in less than 30 minutes of reaction, in the absence of solvent. However, when acetonitrile was employed as an extractive solvent, the desulfurization was increased considerably. Under the reaction conditions, activated catalyst and acetonitrile, solvent to oil ratio $1: 6$, could remove approximately $100 \%$ of quinoline, $95 \%$ of sulfur from 500 -ppmw model oil, $87 \%$ of sulfur from 1500-ppmw model oil in less than $30 \mathrm{~min}$. The catalyst is very active in ECODS and can be reused fifth times from 500-ppmw model oil and third times from 1500-ppmw model oil without an important decrease in activity. The ECODS could remove $83 \%$ of total sulfur from 1235-ppmw-S real diesel.
\end{abstract}

\footnotetext{
Corresponding author: Tel.: +989131700311; E-mail address: f_banisharif@alumni.iust.ac.ir, f.banisharifdehkordey@gmail.com (F. Banisharif)
} 
Keywords: Extractive-oxidative desulfurization, Dawson-type polyoxometalate, Alkyl ammonium silicate, Sulfur compound, Nitrogen compound

\section{Introduction}

Sulfur removal from fuel oil has gained significant attention due to the global environmental awareness about the serious consequence of burning sulfur-bearing fuels. Environmental protocols in this regard become stricter day by day [1,2]. There are various techniques for the desulfurization of oil fuels such as selective adsorption, extractive separation, hydrodesulfurization (HDS) and oxidative desulfurization (ODS) [3-14]. Among various desulfurization methods, HDS is considered as a common and practical method for sulfur removal in the petroleum refineries $[1,2]$. While to achieve ultra-low sulfur content fuel oil, typical HDS requires more severe conditions such as higher temperature, pressure, hydrogen consumption and large residence time which impose higher operating cost [1-4]. ODS has been confirmed to be one of the most promising and favorable alternative desulfurization processes to achieve ultra-low sulfur content fuels [1-14]. Desulfurization under mild conditions (temperature lower than $100{ }^{\circ} \mathrm{C}$ and atmospheric pressure) in the liquid phase is the utmost advantage of ODS as compared to the conventional HDS. In the ODS reaction, sulfur compounds can be oxidized by the electrophilic addition and then will be removed by a solvent [4-8]. In the ODS process, $\mathrm{H}_{2} \mathrm{O}_{2}$ is the mostly selected oxidant, because its byproduct is water [1-14]. Several kinds of catalysts have been used in the bipolar liquidliquid ODS system in the presence of $\mathrm{H}_{2} \mathrm{O}_{2}$.

In our previous works [1-3], we have shown that an emulsion catalyst acting as a phase transfer agent in the ODS system can be very effective. However, the main problems for these kinds of catalyst are the difficulties in recovery and reusability. Therefore, the use of supported catalysts in ODS processes has been more considered in recent years. Various types of supported catalysts have been studied in the ODS system [4-14] such as $\mathrm{MO}_{\mathrm{x}} / \mathrm{Al}_{2} \mathrm{O}_{3}$ 
[4], Titanium supported catalyst [9]. However, their selectivity for oxidized sulfur compounds is not enough, and some other components are also oxidized [9-14]. Hence, the new type of supported catalysts with high selectivity should be considered in heterogeneous ODS of fuel. Among various catalysts, used together with $\mathrm{H}_{2} \mathrm{O}_{2}$, polyoxometalate (POM or Hetero Poly Acid (HPA)) has been more suggested due to the several advantages such as high selectivity and its potential for desulfurization of satirically hindered sulfur compounds. Furthermore, it is an environmentally friendly catalyst [1-3]. Two common types of POMs, Keggin-type and Dawson-type, were used in oxidation process. Although Keggin-type POMs have gradually become worldwide popular for ODS application [15-20]; few studies paid attention to ODS by Dawson-type POMs. One of the most important subclasses of POM is the vanadium $(\mathrm{V})$ substituted POMs. In fact, $\mathrm{V}^{\mathrm{n}+}$ is the most strongly oxidizing element and can be readily reduced to $\mathrm{V}^{(\mathrm{n}-1)+}$ with concomitant oxidation of an organic substrate. The addition of vanadium is useful to shift POM's reactivity from acid-dominated to redoxdominated, as demonstrated by the oxidation of some organic compounds [1-3]. Some authors have been tried to synthesize supported POM catalyst by immobilization on a silica functionalized alkyl ammonium salts [4-14].

In this work, in continuation of our previous works [1-6] and in order to overcome the problem of reusability of the POM catalyst, the ODS of model oil containing several model S-containing compounds (benzothiophene (BT), dibenzothiophene (DBT) and 4, 6 di-methyl dibenzothiophene (4, 6 DMDBT)) and quinoline (Q) as a model N-containing compound has been studied using a new type of silica (functionalized alkyl ammonium salts) supported polyoxometalate catalyst.

\section{Experimental}

\subsection{Catalysis preparation}


The vanadium substituted Dawson-type phosphotungstate heteropoly acid, $\mathrm{H}_{11} \mathrm{P}_{2} \mathrm{~W}_{13} \mathrm{~V}_{5} \mathrm{O}_{62}$ was synthesized based on our previous works [1-3]. The 0.033 mole ammonium monovanadate and 0.08 mole sodium phosphate were dissolved in $100 \mathrm{~mL}$ deionized water at $40{ }^{\circ} \mathrm{C}$. Thereafter, 0.017 mole sodium tungstate was added, and the $\mathrm{pH}$ was adjusted to 4.4 by adding a certain amount of sulfuric acid ( $1 \mathrm{~mol} / \mathrm{L})$, then the solution was refluxed for 8 hours. The solution was allowed to cool slowly to room temperature. Then, $150 \mathrm{~mL}$ diethyl ether was added, and the mixture was shaken and allowed to separate for 1 hour. The solution was divided into three phases; the red substance at the bottom was a mixture of heteropoly acid and diethyl ether. After evaporation of diethyl ether and drying at $200{ }^{\circ} \mathrm{C}$, a powdered well-Dawson vanadium substituted heteropoly acid was obtained.

The heterogeneous catalyst were synthesized by ionic exchange of quaternary ammonium functionalized silica (Silicycle: SiliaBond ${ }^{\circledR}$ TMA Chloride). An excess (3:1) of heteropoly acid was solubilized in water $(25 \mathrm{~mL})$, and then $4 \mathrm{~g}$ of support was added. The mixture was stirred overnight. The solid was filtered off and washed with demineralized water and dried at $75{ }^{\circ} \mathrm{C}$ in vacuum oven.

\subsection{Catalyst characterization}

The metal content of the synthesized catalyst was determined using X-ray fluorescence (XRF) spectroscopy using an ARL analyzer with an Rh anode of an X-ray tube and VRA analyzer with a $\mathrm{Cr}$ anode of an X-ray tube. Fourier transform infrared (FT-IR) was used to confirm the formation of a Dawson-type structure. FT-IR spectra were recorded on a Shimadzu-8400S FT-IR spectrometer using 3 wt. \% KBr pellets. Ultraviolet-visible diffuse reflectance spectroscopy (UV-vis DRS) was recorded on a Varian Cary 5000 UV-vis spectrophotometer equipped with an integrating sphere to distinguish the electronic properties of the center-metal ions. The $\mathrm{BaSO}_{4}$ was used as the internal standard. X-ray photoelectron (XPS) spectrum was obtained by using VG Escalab $200 \mathrm{R}$ with Al/Mg X-ray source. Pass 
energy was $20 \mathrm{eV}$ and base pressure of analysis chamber was not greater than $1 \times 10^{-} 8 \mathrm{~Pa}$. The spectra were calibrated against the reference binding energy of $\mathrm{C} 1 \mathrm{~s}(284.8 \mathrm{eV})$. Thermogravimetric-differential thermal analysis (TGA) was done using TA-Q500 instrument from room temperature to $600{ }^{\circ} \mathrm{C}$ under pure nitrogen environment at a heating rate of $5{ }^{\circ} \mathrm{C} / \mathrm{min}$.

\subsection{Catalyst activity test}

Two kinds of model diesel were used in this study. The 500 ppmw sulfur containing model oil, named as 500-ppmw-S model oil, contained approximately 646 ppmw BT, 1493.8 ppmw DBT, 646 ppmw 4, 6-DMDBT and 445 ppmw quinoline in the 2, 2, 4-trimethyl pentane containing $20 \mathrm{v} . \%$ toluene. The second one included 1500 ppmw sulfur $(2650 \mathrm{ppmw}$ BT, 6150 ppmw DBT, 2650 ppmw 4,6-DMDBT) as well as 1335 ppmw quinoline in the 2, 2, 4-trimethyl pentane containing $20 \mathrm{v} . \%$ toluene. In addition to model oil, the performance of new catalyst has been study in real diesel containing 1235 ppmw sulfur kindly provide by CEPSA (Spain).

The optimized conditions, determined in our previous works [1-4], have been used in this study. In a typical ODS run, the solution was heated to $60{ }^{\circ} \mathrm{C}$. The $7.5 \mathrm{~g} / \mathrm{L}$ supported catalyst and the oxidant, 50 wt. $\% \mathrm{H}_{2} \mathrm{O}_{2}$ (mole ratio of oxidant to oxidized agent, 4) were added to the solution simultaneously at a magnetic stirring speed of $1000 \mathrm{r} / \mathrm{min}$. In a typical extractive oxidative desulfurization (ECODS) run, the mixture, containing model oil and acetonitrile as an extractor (solvent to oil ratio, 1:6) was heated to $70{ }^{\circ} \mathrm{C}$. The $7.5 \mathrm{~g} / \mathrm{L}$ supported catalyst and the oxidant, 50 wt. $\% \mathrm{H}_{2} \mathrm{O}_{2}$ (mole ratio of oxidant to oxidized agent, 4) were then added to the mixture simultaneously at a magnetic stirring speed of $1000 \mathrm{r} / \mathrm{min}$. The sample was taken in the different time and put into an ice chamber to stop the reaction. The catalyst and solvent in the sample were separated by decantation. The performance of reaction was analyzed by a gas chromatography (Agilent, 7890A) coupled with a FID detector using a capillary column $(\mathrm{HP}-5,30 \mathrm{~m} \times 0.32 \mathrm{~mm} \times 0.25 \mu \mathrm{m})$. 
The ECODS of real diesel was run same as model oil under the optimum conditions. After each run, the oil phase was separated by decantation. The sulfur content in real diesel after reaction was determined using X-ray fluorescence spectrometer (ASTM D4294 method).

\section{Results and discussions}

\subsection{Catalyst characterization of supported catalyst}

The metal content of catalyst was determined by XRF analysis. The results demonstrated that the supported catalyst, PWV5/TMA-Si, contained 27.27 wt. \% metal content (24.9 wt. \% tungsten, 2.37 wt. \%).

Fig. 1(a) and (b) shows the FT-IR pattern of supported catalyst and the comparison between FT-IR patterns of supported catalyst and polyoxometalate patterns. These figures illustrates that new peaks has been appeared in region between 780 to $1100 \mathrm{~cm}^{-1}$. They are related to vanadium substituted Dawson type POM on the surface of functionalized silica. Other peaks are related to quaternary ammonium (1447- $1468 \mathrm{~cm}^{-1}$ and $2333-2360 \mathrm{~cm}^{-1}$ ) and hydroxide group $\left(\sim 3442 \mathrm{~cm}^{-1}\right)$ [1-6].

The DRS-UV-vis spectrum of PWV5/TMA-Si demonstrates absorptions associated with the ligand metal charge transfer (LMCT) from the oxygen to the transition metal ion of POM (Fig. 2). PWV5/TMI-Si spectrum shows two absorption band at 257 and $355 \mathrm{~nm}$, which is characteristic of vanadium-substituted Dawson-type polyoxometalate. The first one is assigned to LMCT from oxygen to phosphorous and tungsten. The second one is attributed to LMCT from oxygen to vanadium [1-4].

The binding energies of V2p (V2 $\left.\mathrm{p}_{3 / 2}: 517.08 \mathrm{eV}, \mathrm{V} 2 \mathrm{p}_{1 / 2}: 524.11 \mathrm{eV}\right)$ and $\mathrm{W} 4 \mathrm{f}\left(\mathrm{W}_{4} \mathrm{f}_{7 / 2}\right.$ : $35.23 \mathrm{eV}, \mathrm{W} 4 \mathrm{f}_{5 / 2}: 37.12 \mathrm{eV}$ ) in XPS pattern of PWV5/TMA-Si (Figs. 3 (a) and 3(b)) indicate that the ions remain in the highest oxidation state [1-4].

Summing up, all data obtained from FT-IR, UV-DRS-vis and XPS analysis approved that the supported catalyst has been synthesized successfully. 
TGA analysis shows three weight loss (Fig. 4). The first one is related to coordinated water. The two next ones are attributed to the decomposition of vanadium-substituted POM and tri-methyl-propyl ammonium group [2-3].

\subsection{Performance of catalyst}

The blank tests were done to find out the performance of ODS and EODS of both model oils, 500-ppmw-model oil and 1500-ppmw-model oil, in the absence of the new supported catalyst. Figures 5 and 6 reveal that the efficiency of both ODS and EODS of 500-ppmwmodel oil and 1500-ppmw-model oil were not enough to achieve ultra-low sulfur containing (ULS) fuels. Therefore, in continuous, the new supported catalyst was used in both ODS and EODS process. The presence of catalyst improved the efficiency of ODS and EODS of model oils. The catalytic oxidative desulfurization (CODS) was able to remove $100 \%$ of quinoline from both model oils. CODS achieves around $80 \%$ removal of sulfur from 500-ppmw-model oils (Fig. 7(a)). The increase in sulfur content of model oil from 500 ppmw to 1500 ppmw decreased efficiency of system around $12.5 \%$ (Figs. 7(a) and 7(b)). In order to improve the efficiency of desulfurization of fuels, acetonitrile was used simultaneously by the new supported catalyst (Figs 8(a) and 8(b)). Extractive-catalytic oxidative desulfurization (ECODS) was able to remove $95 \%$ of sulfur and $100 \%$ of quinolone from 500-ppmw-model oil after less than 30 minutes. The increase in sulfur content of model oil reduced the efficiency of system same as its negative effect on the CODS process. The new ECODS could reduce the sulfur content of system from 1500 ppmw to about 195 ppmw after less than 30 minutes. It could be achieved ULS diesel by repeat ECODS process.

The reusability of ECODS was also studied. Fig. 9(a) demonstrates that the new ECODS system containing PWV5/TMA-Si had a good reusability. It could be reused 5 times with negligible activity lost and loss of catalyst after each run. The increase in sulfur content 
reduced reusability of catalyst. The new ECODS could be reused three time with the low activity lost from 1500-ppmw-model oil (Fig. 9(b)).

The performance of new ECODS was also studied for real diesel oil (Fig. 10). The results showed that it could reduce the sulfur content of 1235-ppmw-S real diesel oil to below 200 ppmw. The reusability of new ECODS of real fuel was good. It could be reused three times without a significant decrease in activity and treatment after each recycle steps. The result also revealed that the important loss of catalyst was not seen during the recycle runs.

The activity lost after several recycle runs can be referred to catalyst loss during recycling and blockage of catalyst surface. The XPS analysis also showed that binding energy of V2 $\mathrm{p}_{3 / 2}$ peaks were pretty constant around $517-516 \mathrm{eV}$ that indicate no change in the oxidation state of the vanadium from fresh to after $1^{\text {st }}$ run after $5^{\text {th }}$ run respectively (Fig 11(a)).

The transformations of peaks of $\mathrm{W} 4 \mathrm{f}_{7 / 2}$ from $35.2 \mathrm{eV}$ (Fresh system) to $35.7 \mathrm{eV}\left(1^{\text {st }}\right.$ and $5^{\text {th }}$ runs) were attributed to the formation of peroxometalates moieties with hydrogen peroxide in organic solution (Fig. 11(b)). So, it was found out that tungstate took a main role in transfer of oxygen from $\mathrm{H}_{2} \mathrm{O}_{2}$ to $\mathrm{S} / \mathrm{N}$-compounds selectively and catalyzed the EODS process [1-4]. We detect a decrease in the signal intensity of the peaks of $\mathrm{V}$ and $\mathrm{W}$ after reaction, but the Surf ace atomic ratio $\mathrm{V} / \mathrm{Si}$ and $\mathrm{W} / \mathrm{Si}$ did not change significantly. This finding indicates that surface of the catalyst can be covered by organic compunds.

\section{Conclusions}

For the first time, ECODS of several model S-containing compounds (BT, DBT and 4, 6 DMDBT) and quinoline as a nitrogen containing compound from model oil and real diesel oil using new kinds of supported catalyst was studied. The selected solvent used to synthesize model oil was quite realistic because it had a 1-ring aromatic compound $(20 \mathrm{v} . \%$ toluene in iso-octane) that made the process difficult. In order to overcome initial water content of system, the oxidant employed was 50 wt. \% hydrogen peroxide (mole ratio oxidant to 
oxidized agents, 4). The new supported catalyst, synthesized by ion-exchanged, was a vanadium-substituted Dawson-type polyoxometalate tethered on silica functionalized by tri methyl-propyl ammonium groups (TMA-Si). The heterogeneous catalyst was tested using soft reaction conditions: temperature range below $100{ }^{\circ} \mathrm{C}$ and atmospheric pressure. The new supported catalyst was able to activate selectively hydrogen peroxide to oxidize S/N compounds via transfer of tungsten to peroxometalate. The potential of this methodology was illustrated by $\sim 80 \%$ oxidation of total sulfur in 500 -ppmw model oil and $\sim 70 \%$ oxidation of total sulfur in 1500-ppmw model oil after lower than 30 minutes, in the absence of a solvent. However, when acetonitrile was employed as extractor solvent; the desulfurization efficiency was increased clearly. Under the reaction conditions Activated PWV5/Si-TMA and acetonitrile as a solvent, ratio solvent to oil 1:6, was able to remove approximately $95 \%$ of sulfur from 500-ppmw model oil and more than $80 \%$ of sulfur from 1500 -ppmw model oil. The activated PWV5/Si-TMA catalyst was very active in ECODS reaction and could be reused five times without loss of activity from 500-ppmw model oil. The performance of new ECODS of 1235-ppmw real diesel oil was also demonstrated by $\sim 83 \%$ removal of sulfur compound and 3-time reusability without an obvious decrease in activity. 


\section{References}

[1] F. Banisharif, M.R. Dehghani, M.C. Capel-Sanchez, J.M. Campos-Martin, J. Ind. Eng. Chem. 47 (2017) 348-359.

[2] F. Banisharif, M.R. Dehghani, M.C. Capel-Sanchez, J.M. Campos-Martin, Ind. Eng. Chem. Res. 56(14) (2017) 3839-3852.

[3] F. Banisharif, M.R. Dehghani, J.M. Campos-Martin, Energy Fuel 31(5) (2017) 54195427.

[4] J.M. Campos-Martin, M.C. Capel-Sanchez, P. Perez-Presas, J.L.G. Fierro, J. Chem. Technol. Biotechnol. 85(7) (2010) 879-890.

[5] M. Zhang, W. Zhu, H. Li, S. Xun, M. Li, Y. Li, Y. Wei, H. Li, Chin. J. Catal. 37(6) (2016) 971-978.

[6] W. Jiang, D. Zheng, S. Xun, Y. Qin, Q. Lu, W. Zhu, H. Li, Fuel 190 (2017) 1-9.

[7] G. Blanco-Brieva, J.M. Campos-Martin, S.M. Al-Zahrani, J.L.G. Fierro, Fuel 90(1) (2011) 190-197.

[8] S.O. Ribeiro, L.S. Nogueira, S. Gago, P.L. Almeida, M.C. Corvo, B. de Castro, C.M. Granadeiro, S.S. Balula, Appl. Catal., A. Gen. 542 (2017) 359-367.

[9] M.C. Capel-Sanchez, J.M. Campos-Martin, J.L.G. Fierro, Energy Environ. Sci. 3(3) (2010) 328-333.

[10] G. Blanco-Brieva, J.M. Campos-Martin, S.M. Al-Zahrani, J.L.G. Fierro, Fuel 105 (2013) 459-465.

[11] Z. Hasan, J. Jeon, S.H. Jhung, J. Hazard. Mater. 205 (2012) 216-221.

[12] G. Blanco-Brieva, J.M. Campos-Martin, S.M. Al-Zahrani, J.L.G. Fierro, Fuel 113 (2013) 216-220.

[13] N.A. Khan, S.H. Jhung, J. Hazard. Mater.237 (2012) 180-185. 
[14] T.W. Kim, M.J. Kim, F. Kleitz, M. Muraleedharan Nair, R. Guillet-Nicolas, K.E. Jeong, Ho-Jeong Chae, C.U. Kim, S.Y. Jeong, ChemCatChem 4(5) (2012) 687-697.

[15] M. Safa, B. Mokhtarani, H.R. Mortaheb, K.T. Heidar, A. Sharifi, M. Mirzaei, Energy Fuel 31(9) (2017) 10196-10205.

[16] M. Mafi, B. Mokhtarani, M.R. Dehghani, J. Molec. Liq. 221 (2016) 1104-1110.

[17] J.W. Ding, R. Wang, Chinese Chem. Lett. 27(5) (2016) 655-658.

[18] S.O. Ribeiro, D. Julião, L. Cunha-Silva, V.F. Domingues, R. Valença, J.C. Ribeiro, B. de Castro, S.S. Balula, Fuel 166 (2016) 268-275.

[19] B. Bertleff, J. Claußnitzer, W. Korth, P. Wasserscheid, A. Jess, J. Albert, ACS Sustain. Chem. Eng. 5(5) (2017) 4110-4118.

[20] M.A. Rezvani, S. Khandan, N. Sabahi, Energy Fuel. 31(5) (2017) 5472-5481. 


\section{Figure Captions}

Fig.1. (a) FT-IR patterns of supported catalyst, $\mathrm{H}_{11} \mathrm{P}_{2} \mathrm{~W}_{13} \mathrm{~V}_{5} \mathrm{O}_{62} / \mathrm{TMA}-\mathrm{Si}$, (b) Comparison between FT-IR spectrum of TMA-Si and supported catalyst.

Fig. 2. UV spectrum of supported catalyst, $\mathrm{H}_{11} \mathrm{P}_{2} \mathrm{~W}_{13} \mathrm{~V}_{5} \mathrm{O}_{62} / \mathrm{TMA}-\mathrm{Si}$.

Fig. 3. XPS spectrum of (a) V2p and (b) W4f.

Fig. 4. TGA analysis of $\mathrm{H}_{11} \mathrm{P}_{2} \mathrm{~W}_{13} \mathrm{~V}_{5} \mathrm{O}_{62} / \mathrm{TMA}-\mathrm{Si}$.

Fig. 5. Blank activity test of 500-ppmw-model oil at $70{ }^{\circ} \mathrm{C}$ (a) Only oxidizer, 50 wt. $\% \mathrm{H}_{2} \mathrm{O}_{2}$, mole ratio of oxidizer to oxidized agent $=4$, (b) Only oxidizer, 50 wt. $\% \mathrm{H}_{2} \mathrm{O}_{2}$, and acetonitrile, solvent to oil volume ratio $=1: 6$.

Fig. 6. Blank activity test of 1500 -ppmw-model oil at $70{ }^{\circ} \mathrm{C}$ (a) Only oxidizer, 50 wt. $\% \mathrm{H}_{2} \mathrm{O}_{2}$, mole ratio of oxidizer to oxidized agent $=4$, (b) Only oxidizer, 50 wt. $\% \mathrm{H}_{2} \mathrm{O}_{2}$, and acetonitrile, solvent to oil volume ratio $=1: 6$.

Fig. 7. One-pot catalytic oxidative desulfurization of (a) 500-ppmw-model oil and (b) 1500ppmw-model oil (oxidizer, 50 wt. $\% \mathrm{H}_{2} \mathrm{O}_{2}$, mole ratio of oxidizer to oxidized agent, temperature $70{ }^{\circ} \mathrm{C}$, catalyst dosage, $\left.7.5 \mathrm{~g} / \mathrm{L}\right)$.

Fig. 8. One-pot extractive-catalytic oxidative desulfurization of (a) 500-ppmw-model oil and (b) 1500-ppmw-model oil (oxidizer, $50 \mathrm{wt} . \% \mathrm{H}_{2} \mathrm{O}_{2}$, mole ratio of oxidizer to oxidized agent, acetonitrile as a extractor solvent, solvent to oil volume ratio $=1: 6$, temperature $70{ }^{\circ} \mathrm{C}$, catalyst dosage, $7.5 \mathrm{~g} / \mathrm{L})$.

Fig. 9. Reusability of extractive-catalytic oxidative desulfurization of (a) 500-ppmw-model oil and (b) 1500-ppmw-model oil without any treatment after each run (oxidizer, 50 wt.\% $\mathrm{H}_{2} \mathrm{O}_{2}$, mole ratio of oxidizer to oxidized agent, acetonitrile as a extractor solvent, solvent to oil volume ratio $=1: 6$, temperature $70{ }^{\circ} \mathrm{C}$, catalyst dosage, $7.5 \mathrm{~g} / \mathrm{L}$, time: $30 \mathrm{~min}$ ).

Fig. 10. Reusability of extractive-catalytic oxidative desulfurization of diesel fuel without any treatment after each run (oxidizer, 50 wt. $\% \mathrm{H}_{2} \mathrm{O}_{2}$, mole ratio of oxidizer to oxidized 
agent, acetonitrile as a extractor solvent, solvent to oil volume ratio $=1: 6$, temperature $70{ }^{\circ} \mathrm{C}$, catalyst dosage, $7.5 \mathrm{~g} / \mathrm{L}$, time: $30 \mathrm{~min})$.

Fig. 11. XPS spectra of (a) V2p of fresh catalyst and after $1^{\text {st }}$ and $5^{\text {th }}$ runs and (b) W4f of fresh catalyst and after $1^{\text {st }}$ and $5^{\text {th }}$ runs. 
(a)

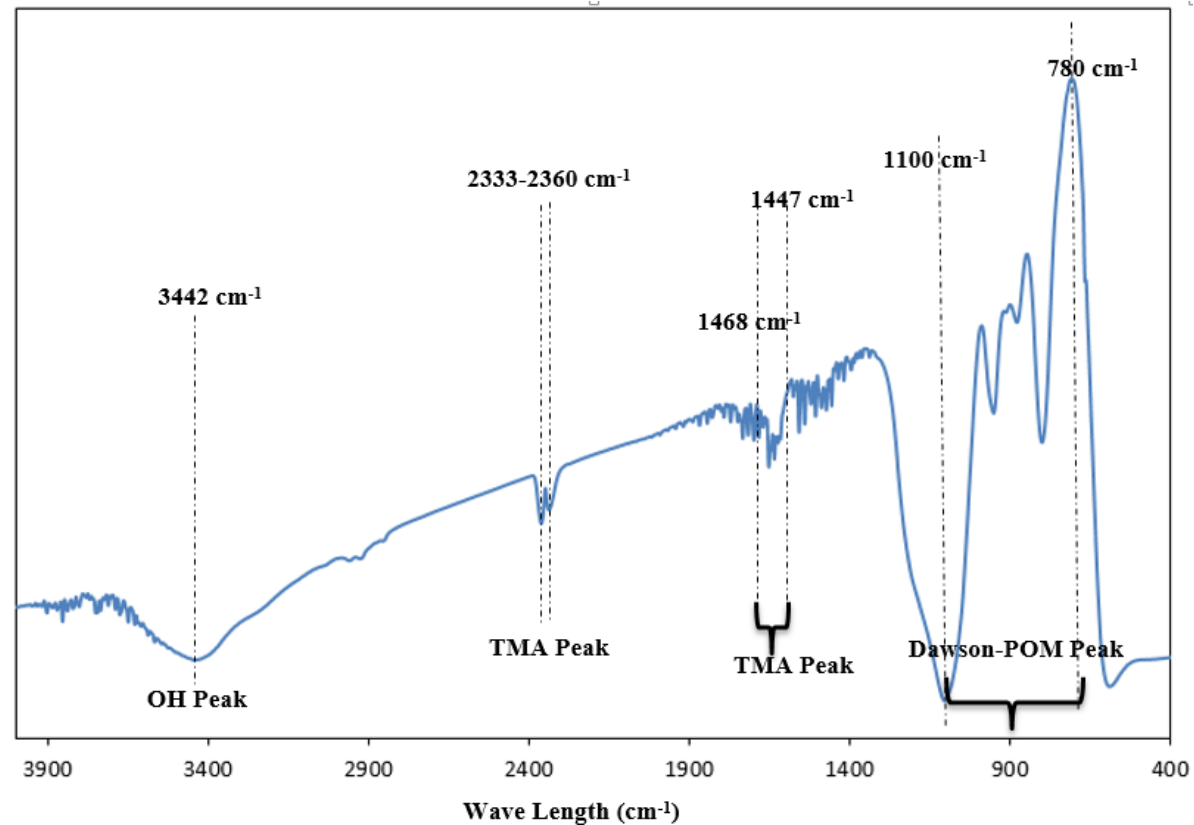

(b)

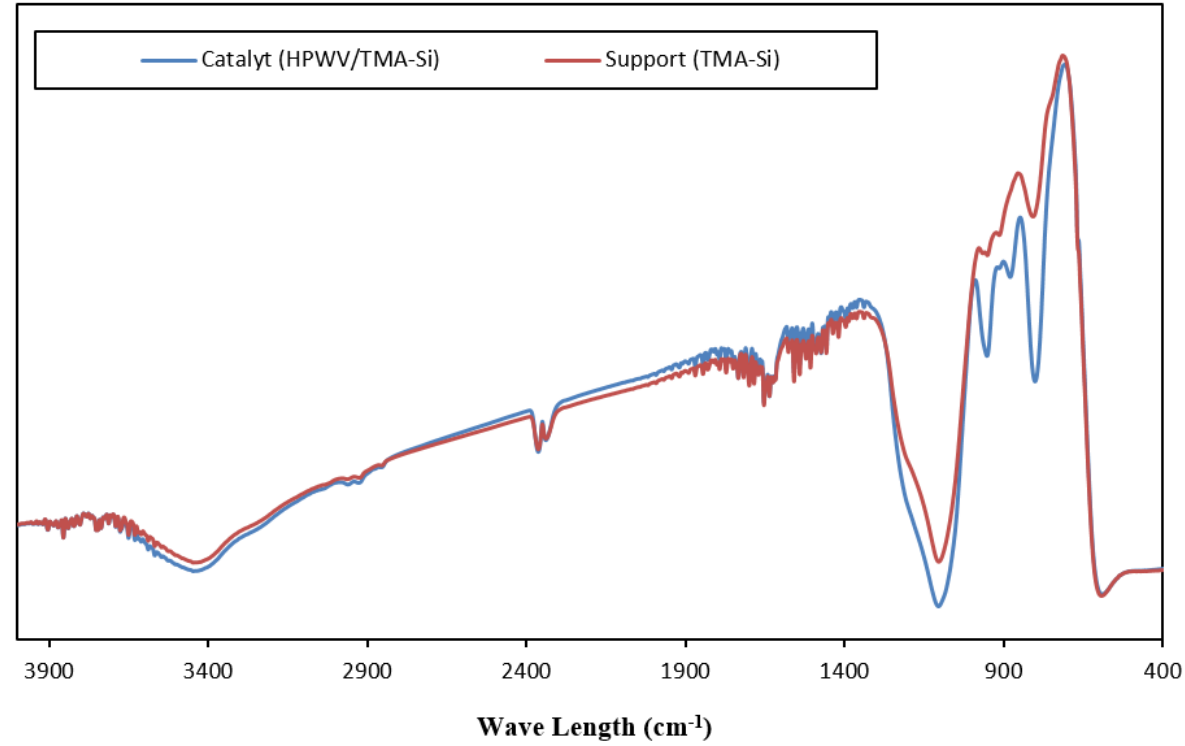

Fig.1. (a) FT-IR patterns of supported catalyst, $\mathrm{H}_{11} \mathrm{P}_{2} \mathrm{~W}_{13} \mathrm{~V}_{5} \mathrm{O}_{62} / \mathrm{TMA}-\mathrm{Si}$, (b) Comparison between FT-IR spectrum of TMA-Si and supported catalyst. 


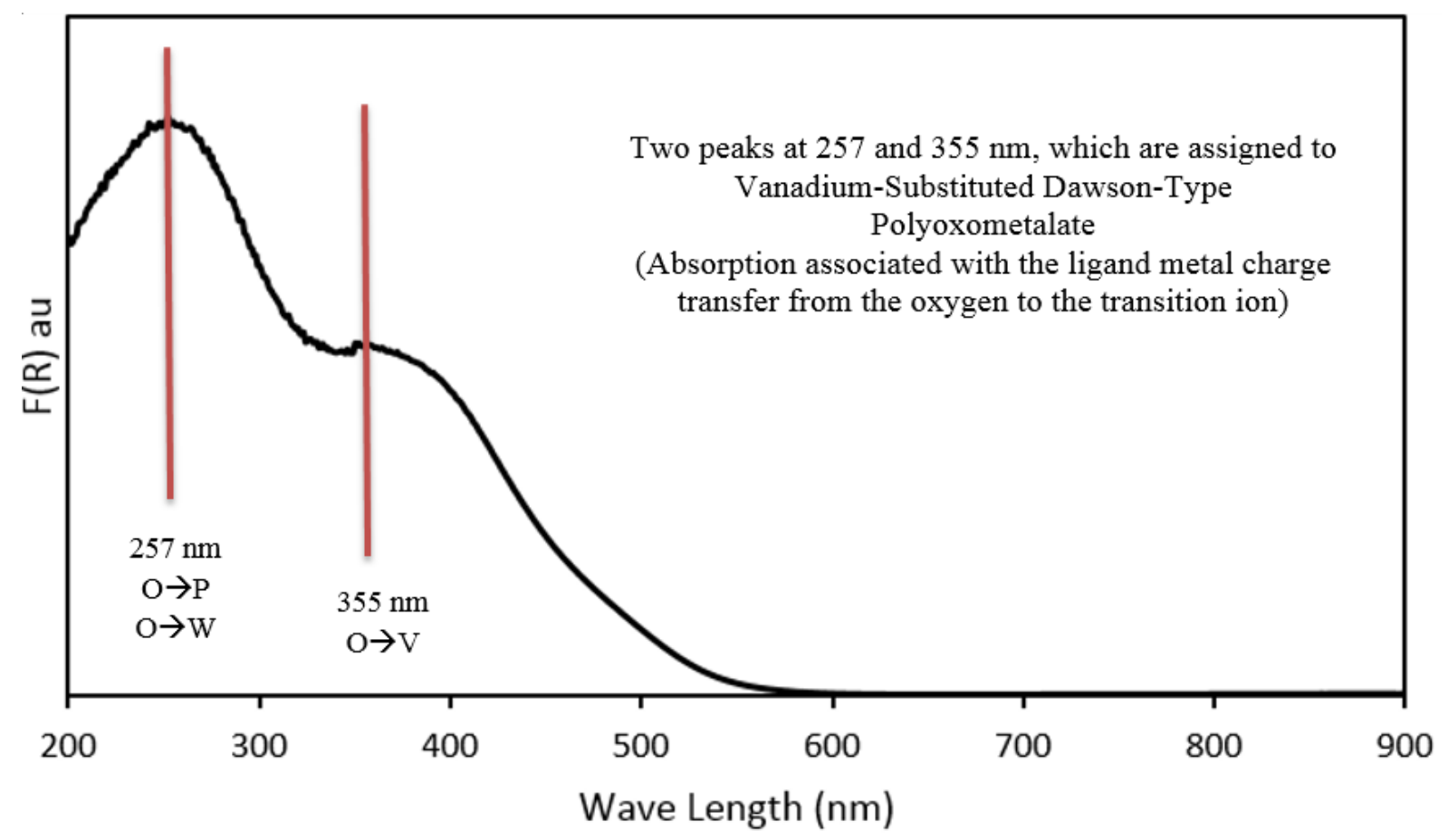

Fig. 2. UV spectrum of supported catalyst, $\mathrm{H}_{11} \mathrm{P}_{2} \mathrm{~W}_{13} \mathrm{~V}_{5} \mathrm{O}_{62} / \mathrm{TMA}-\mathrm{Si}$. 
(a)

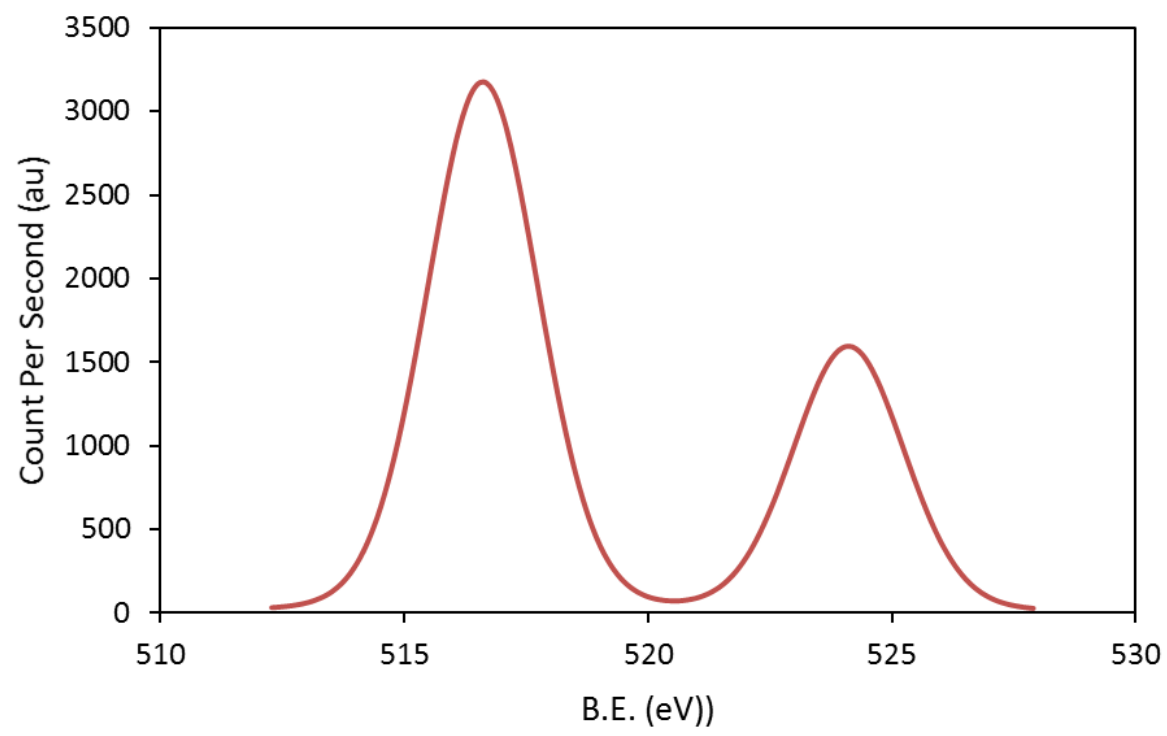

(b)

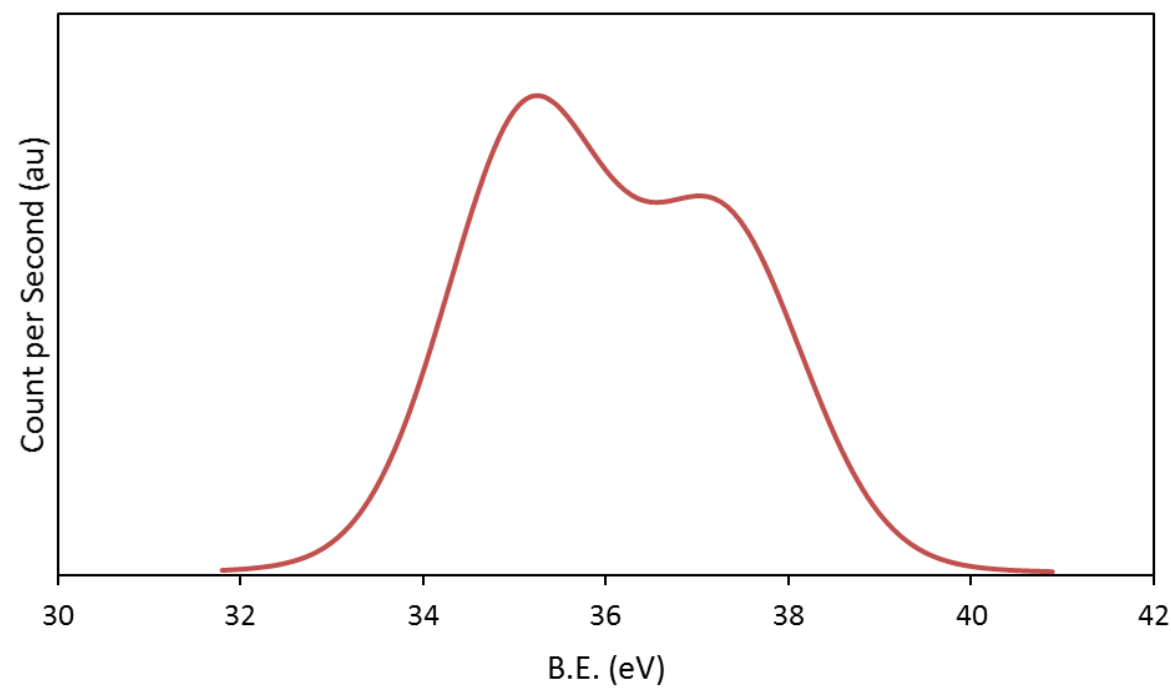

Fig. 3. XPS spectrum of (a) V2p and (b) W4f. 


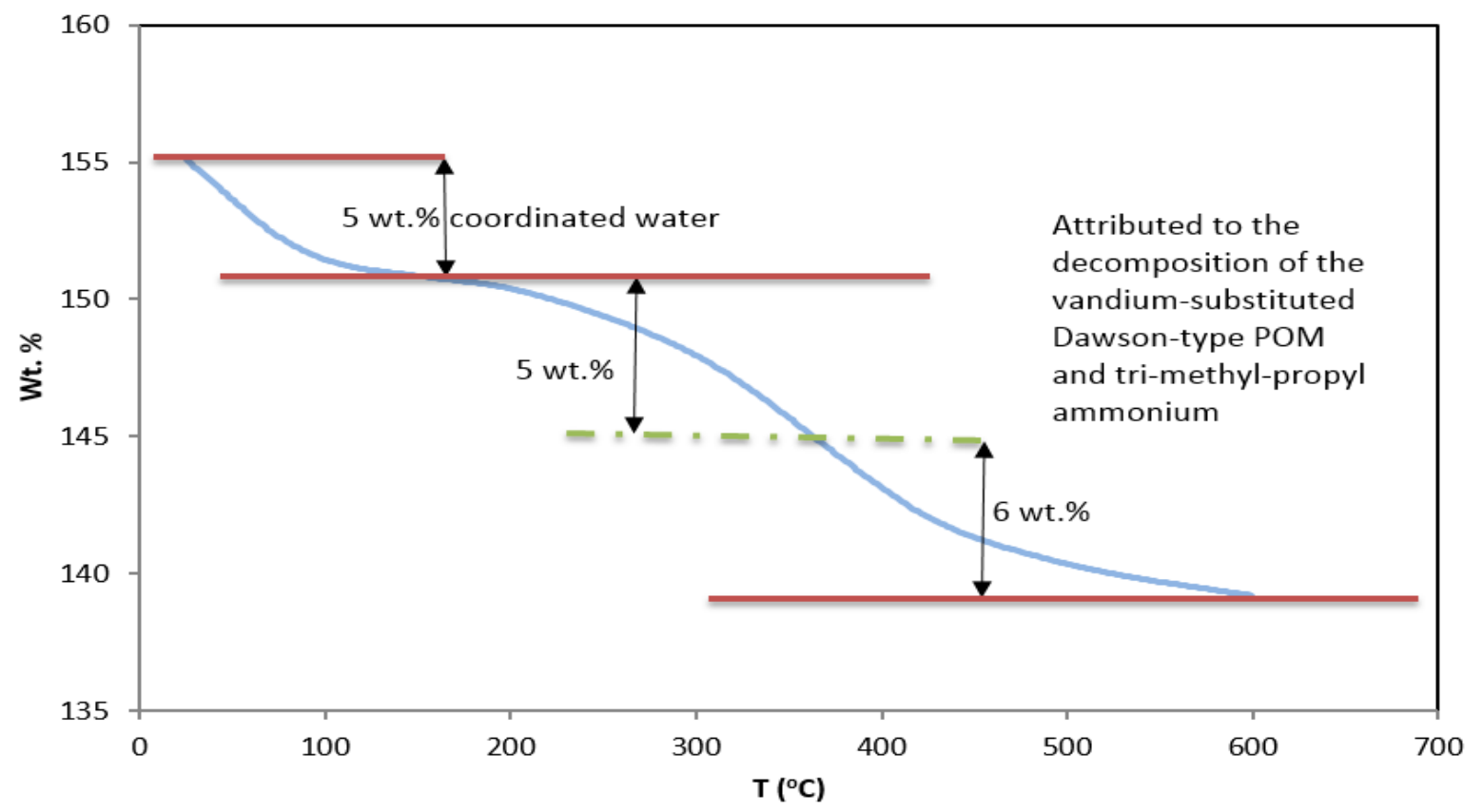

Fig. 4. TGA analysis of $\mathrm{H}_{11} \mathrm{P}_{2} \mathrm{~W}_{13} \mathrm{~V}_{5} \mathrm{O}_{62} / \mathrm{TMA}-\mathrm{Si}$. 
(a)

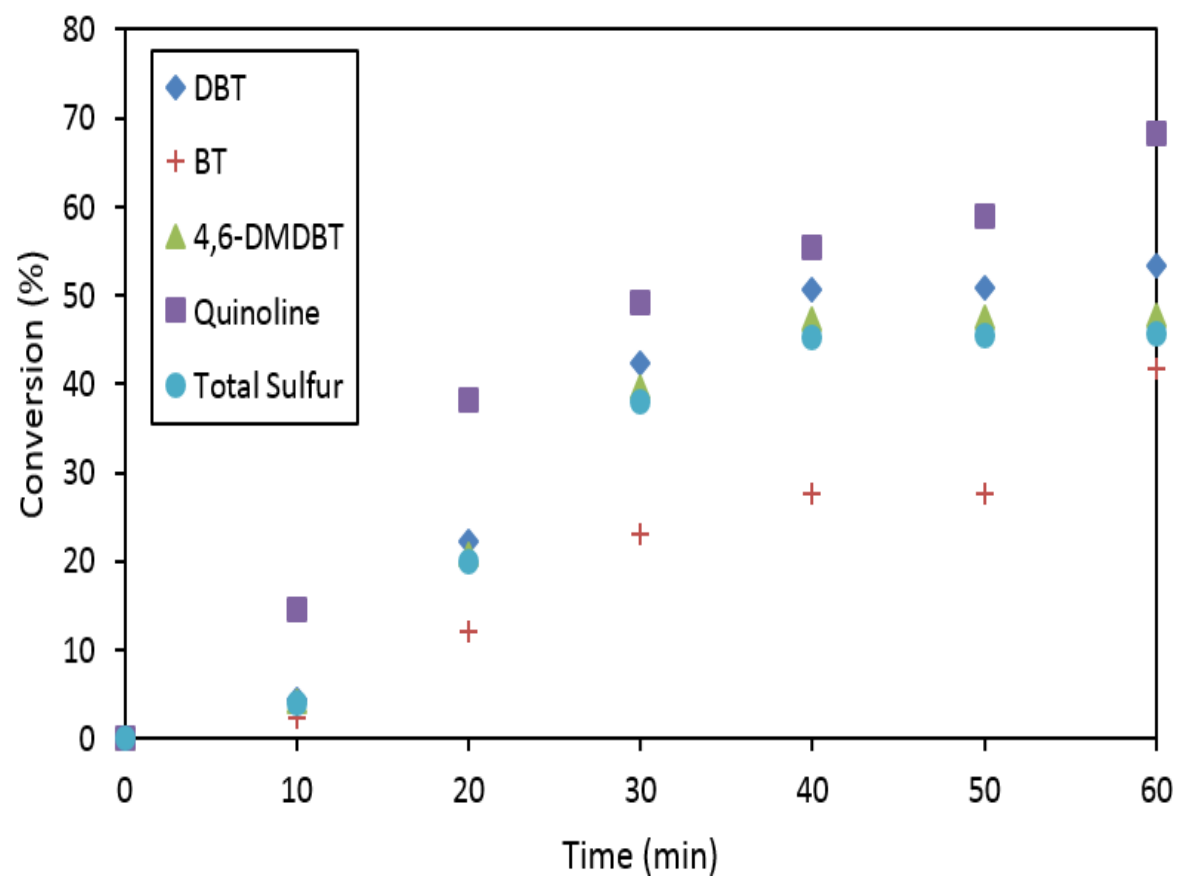

(b)

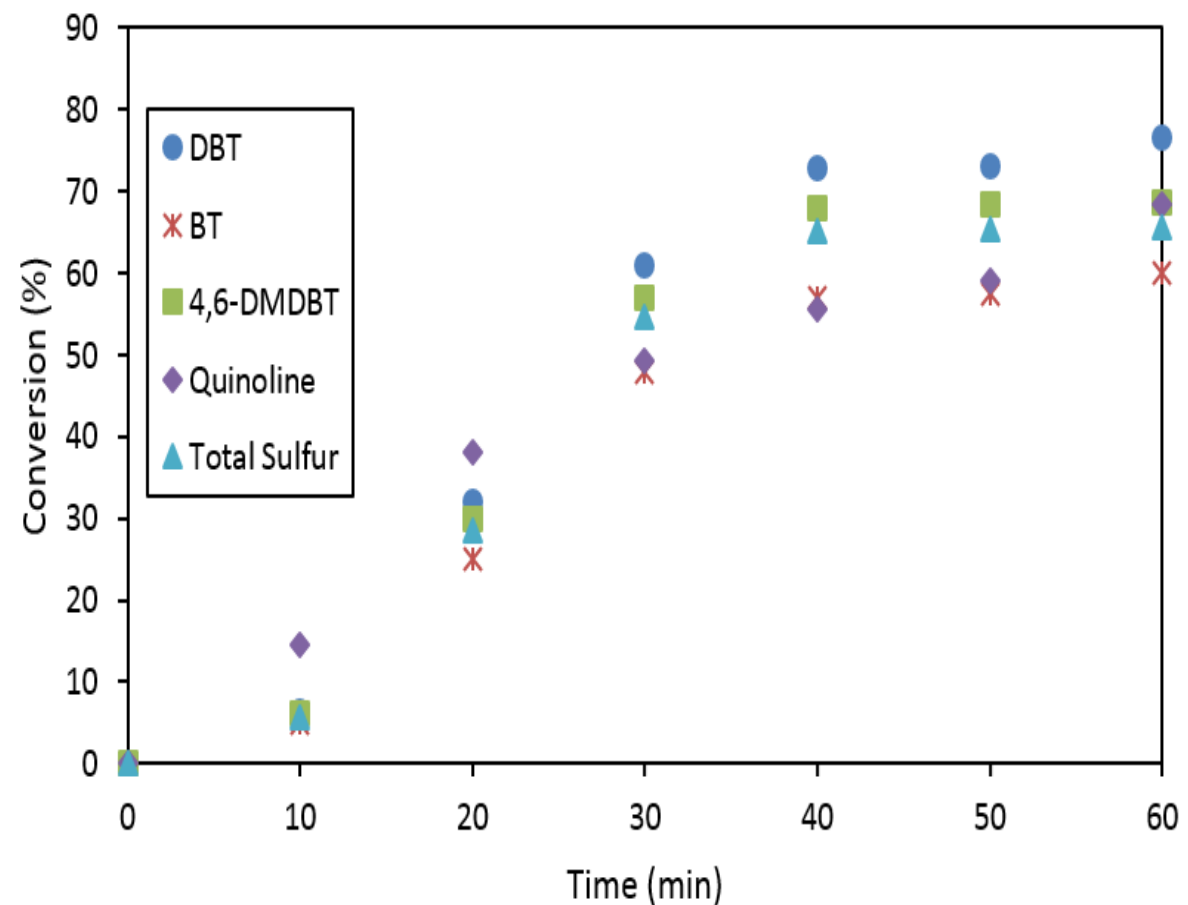

Fig. 5. Blank activity test of 500-ppmw-model oil at $70{ }^{\circ} \mathrm{C}$ (a) Only oxidizer, 50 wt. $\% \mathrm{H}_{2} \mathrm{O}_{2}$, mole ratio of oxidizer to oxidized agent $=4$, (b) Only oxidizer, 50 wt. $\% \mathrm{H}_{2} \mathrm{O}_{2}$, and acetonitrile, solvent to oil volume ratio $=1: 6$. 
(a)

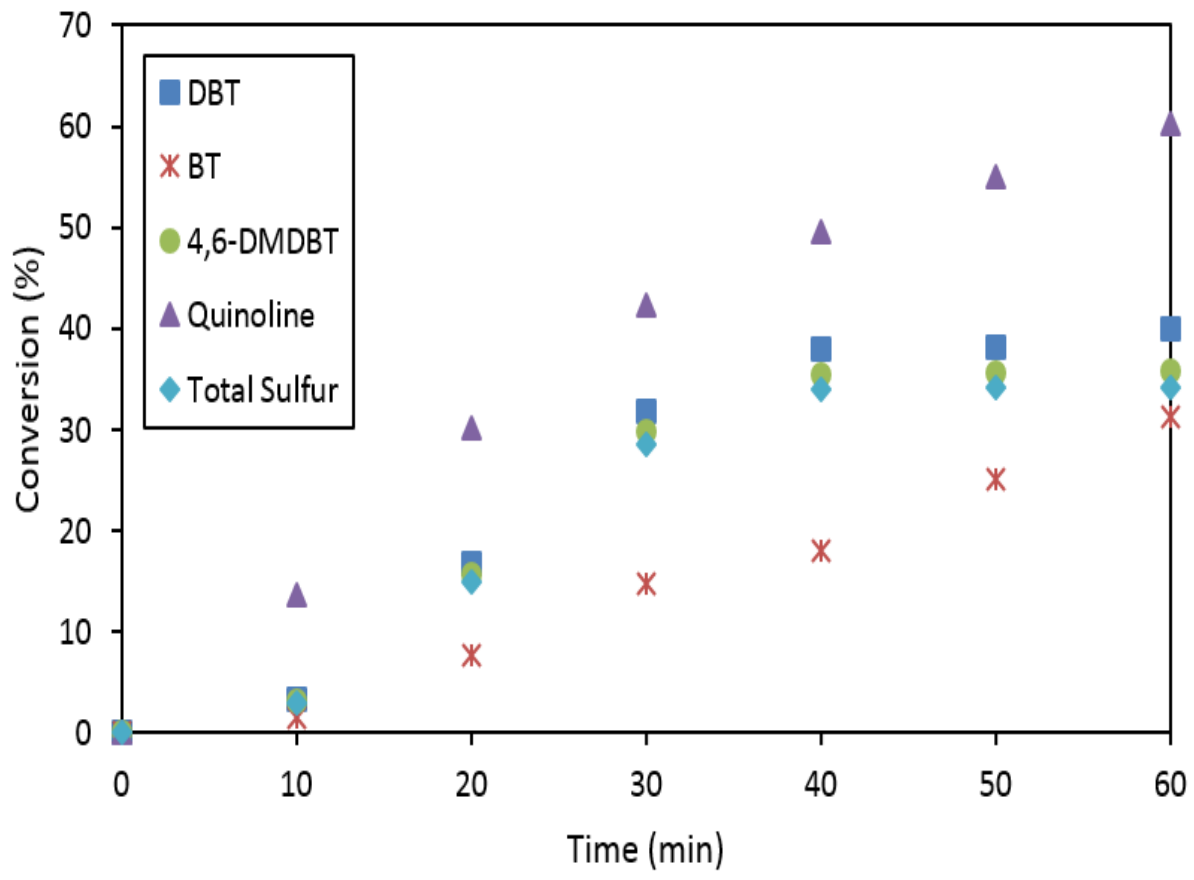

(b)

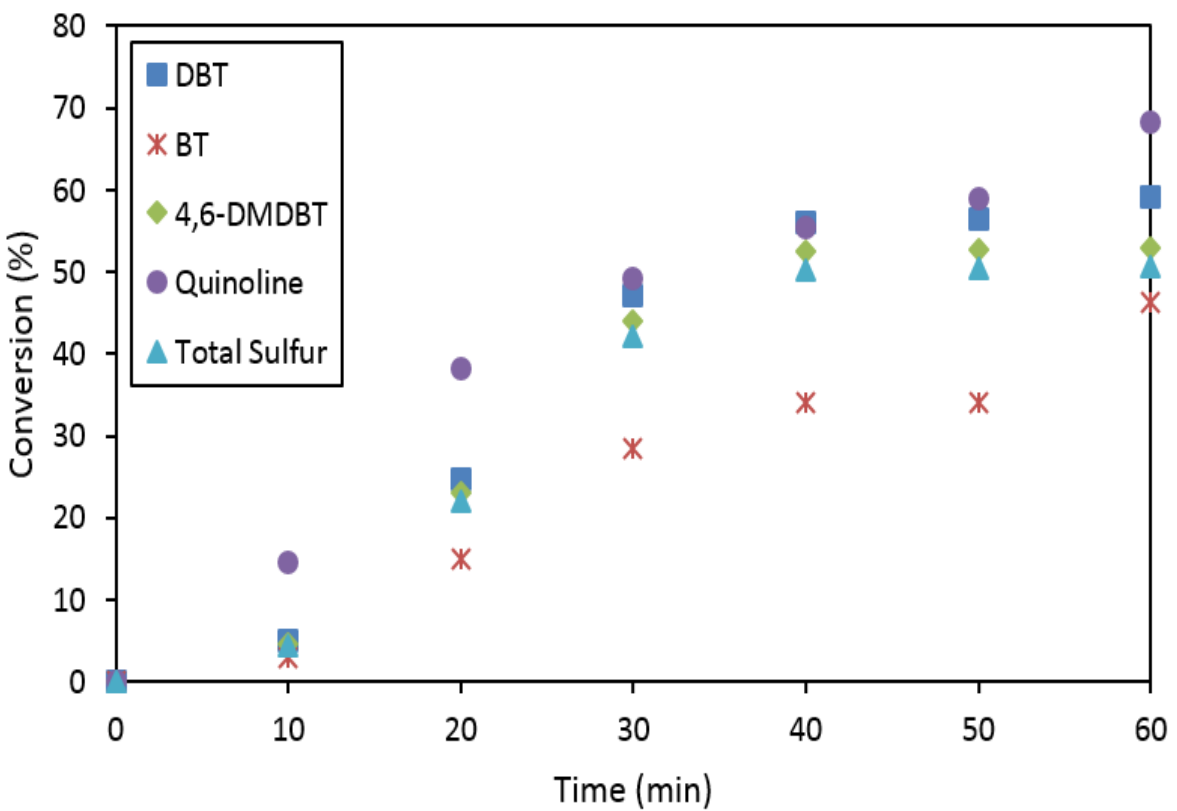

Fig. 6. Blank activity test of 1500-ppmw-model oil at $70{ }^{\circ} \mathrm{C}$ (a) Only oxidizer, 50 wt. $\% \mathrm{H}_{2} \mathrm{O}_{2}$, mole ratio of oxidizer to oxidized agent $=4$, (b) Only oxidizer, 50 wt. $\% \mathrm{H}_{2} \mathrm{O}_{2}$, and acetonitrile, solvent to oil volume ratio $=1: 6$. 
(a)

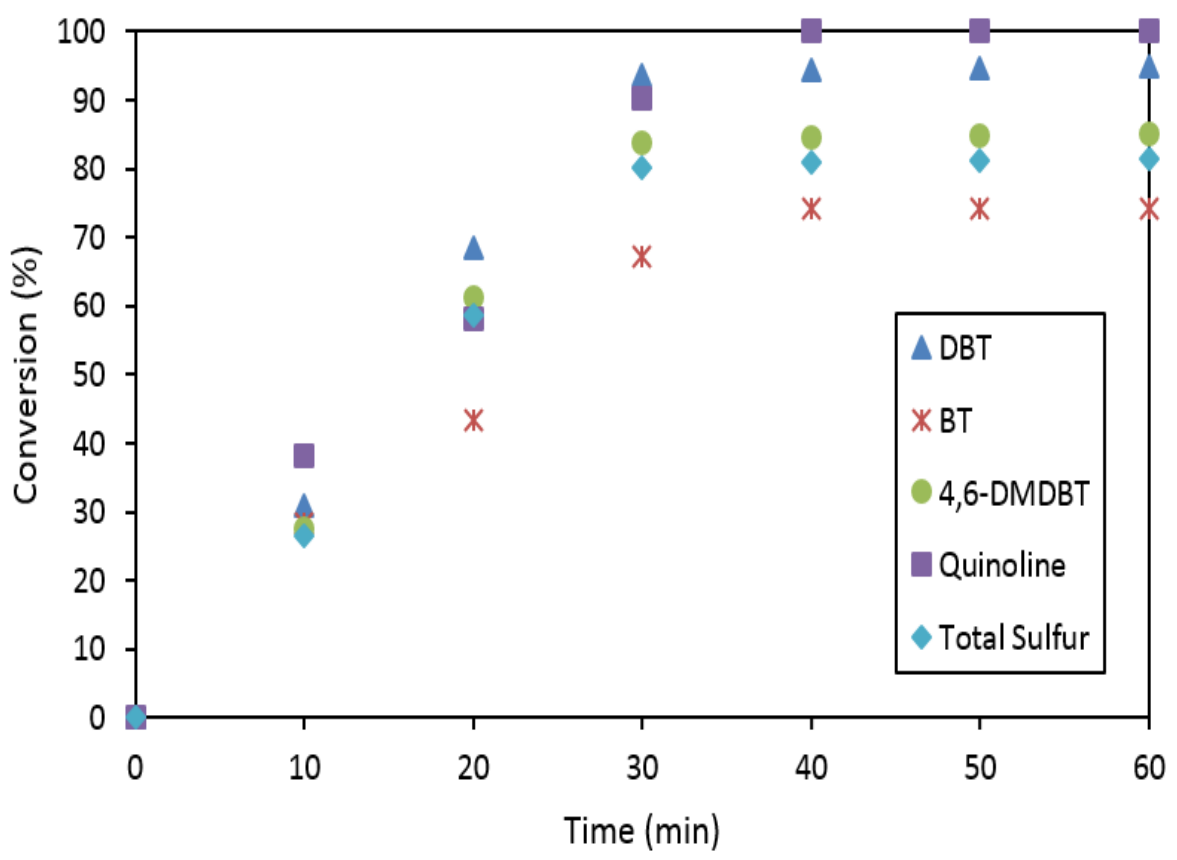

(b)

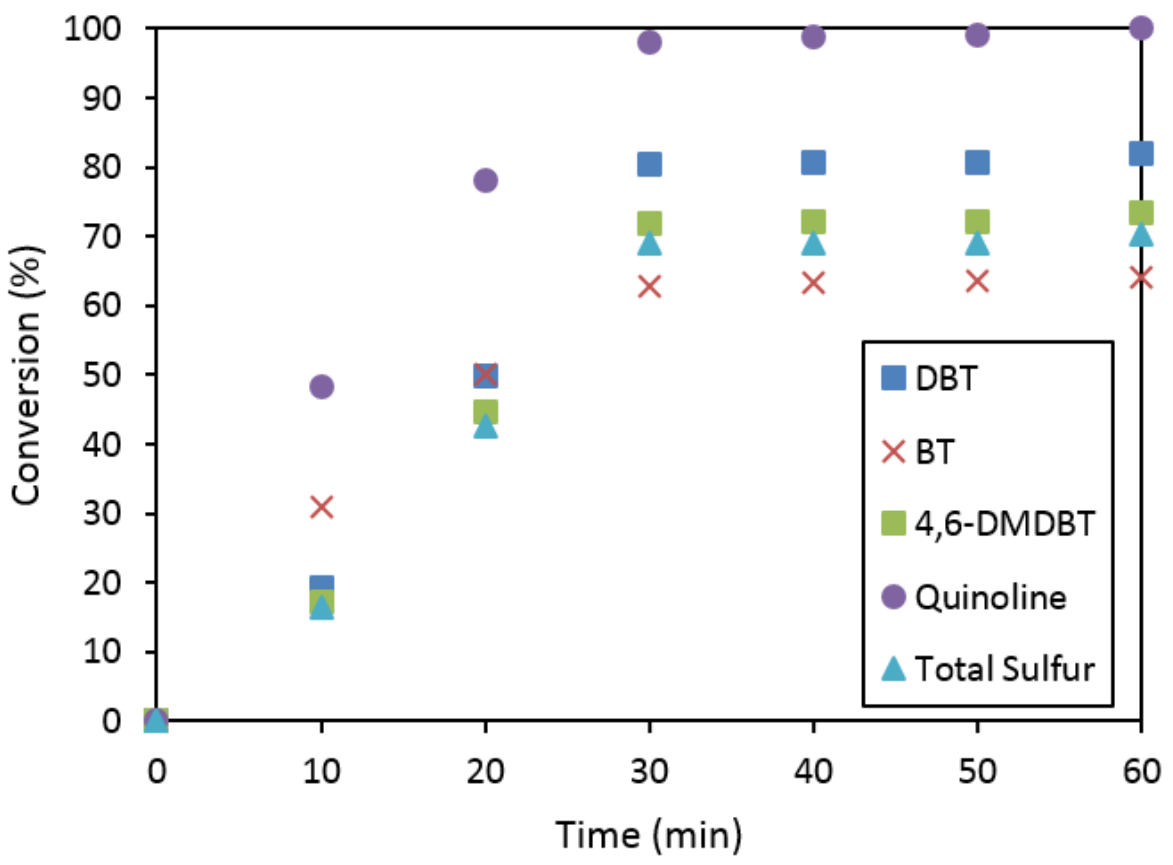

Fig. 7. One-pot catalytic oxidative desulfurization of (a) 500-ppmw-model oil and (b) 1500ppmw-model oil (oxidizer, 50 wt. $\% \mathrm{H}_{2} \mathrm{O}_{2}$, mole ratio of oxidizer to oxidized agent, temperature $70{ }^{\circ} \mathrm{C}$, catalyst dosage, $7.5 \mathrm{~g} / \mathrm{L}$ ). 
(a)

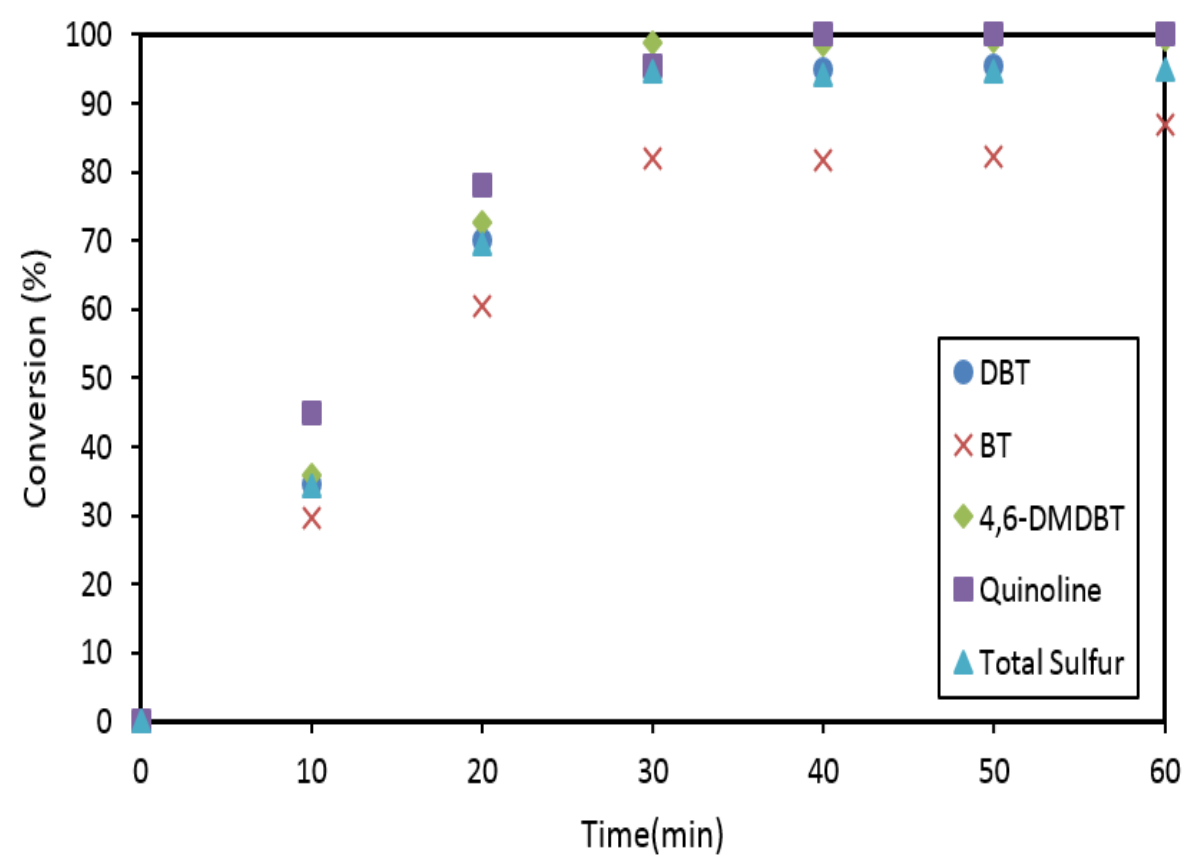

(b)

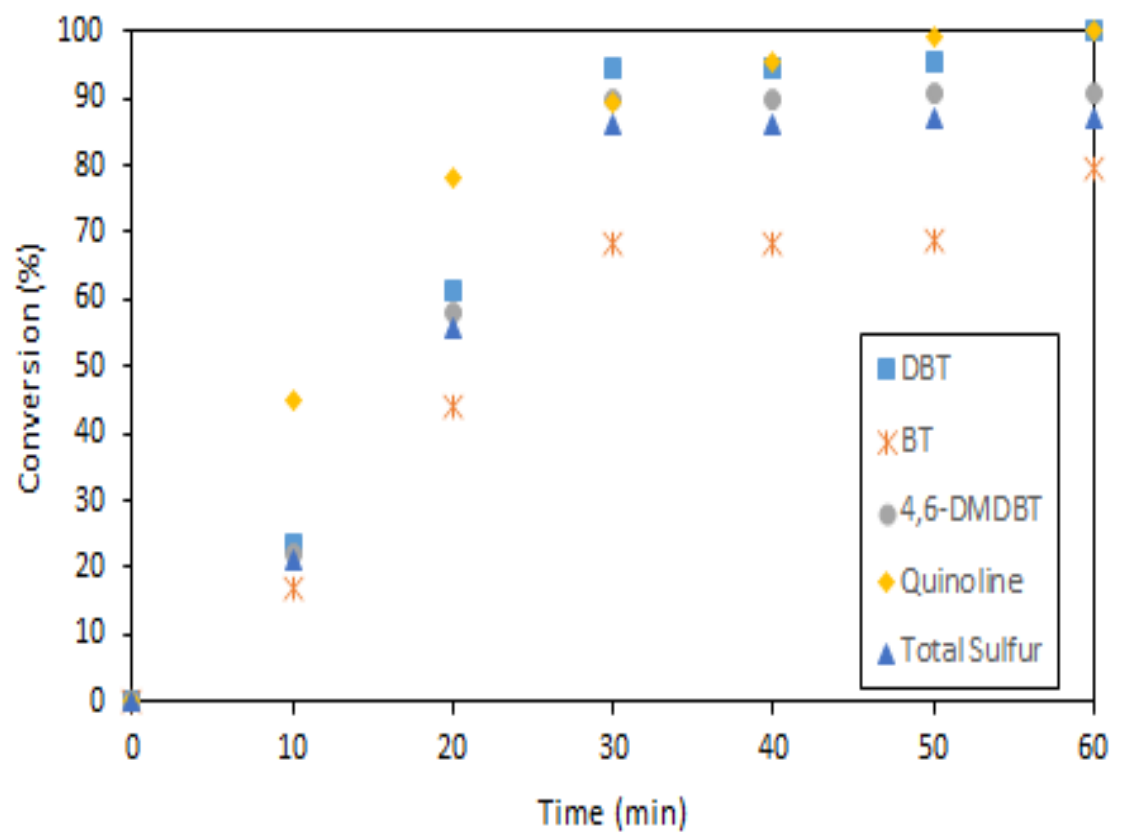

Fig. 8. One-pot extractive-catalytic oxidative desulfurization of (a) 500-ppmw-model oil and (b) 1500-ppmw-model oil (oxidizer, $50 \mathrm{wt} . \% \mathrm{H}_{2} \mathrm{O}_{2}$, mole ratio of oxidizer to oxidized agent, acetonitrile as a extractor solvent, solvent to oil volume ratio $=1: 6$, temperature $70{ }^{\circ} \mathrm{C}$, catalyst dosage, $7.5 \mathrm{~g} / \mathrm{L})$. 
(a)

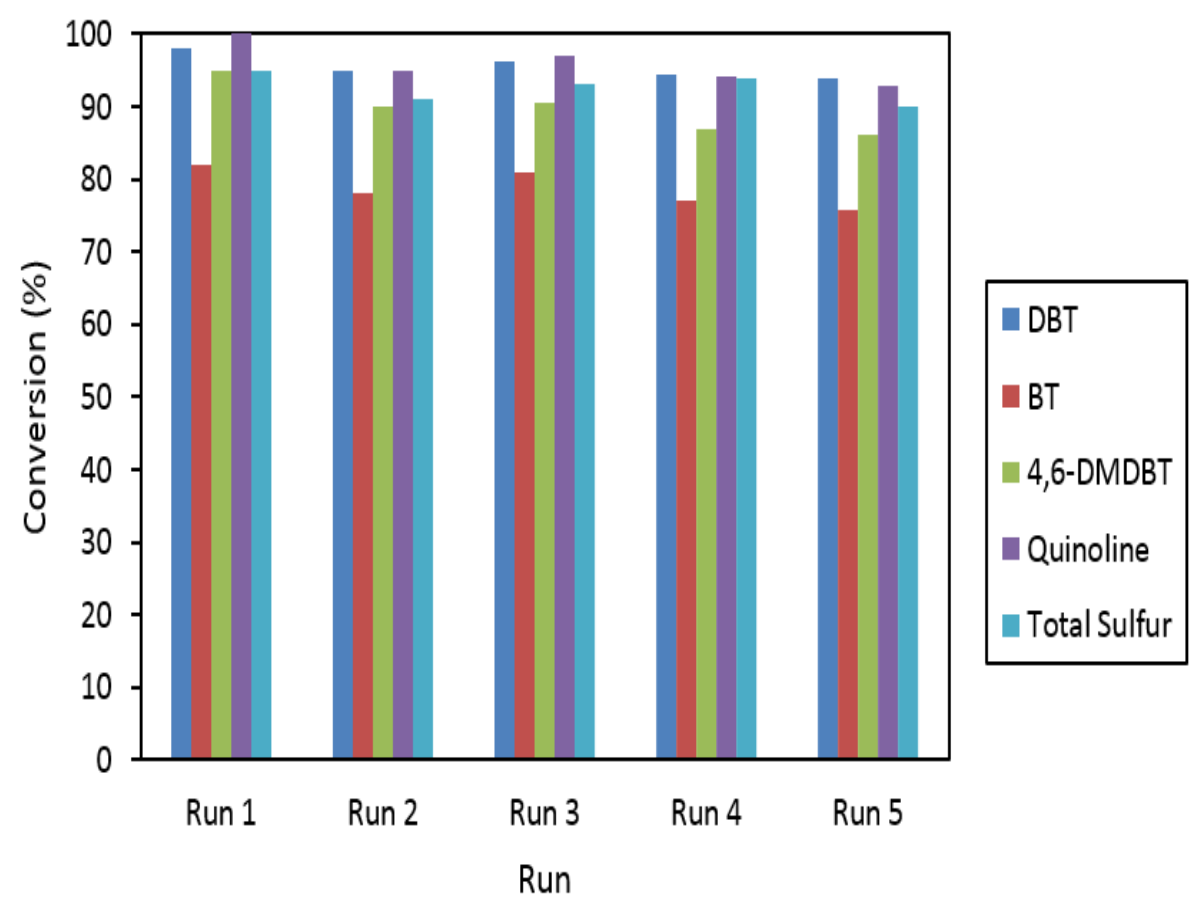

(b)

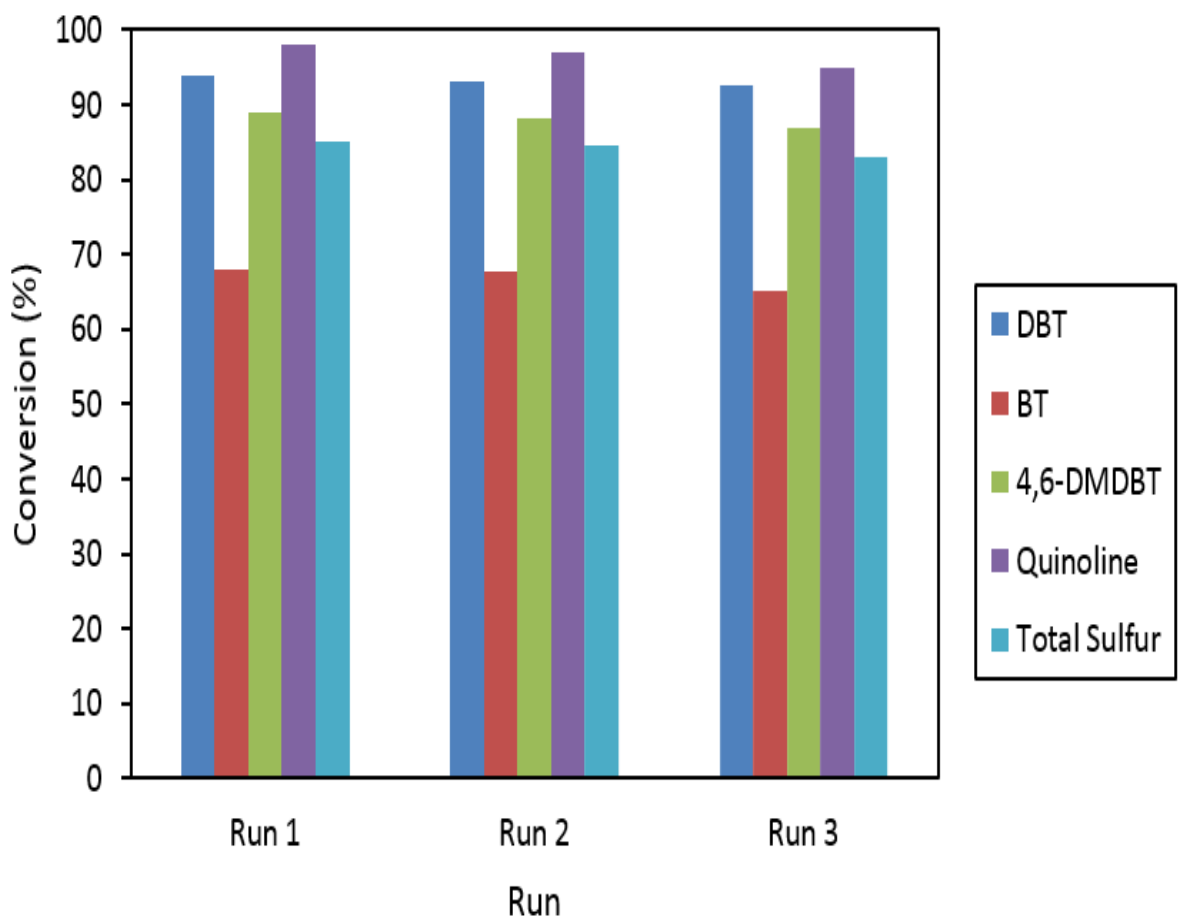

Fig. 9. Reusability of extractive-catalytic oxidative desulfurization of (a) 500-ppmw-model oil and (b) 1500-ppmw-model oil without any treatment after each run (oxidizer, 50 wt.\% $\mathrm{H}_{2} \mathrm{O}_{2}$, mole ratio of oxidizer to oxidized agent, acetonitrile as a extractor solvent, solvent to oil volume ratio $=1: 6$, temperature $70{ }^{\circ} \mathrm{C}$, catalyst dosage, $7.5 \mathrm{~g} / \mathrm{L}$, time: $30 \mathrm{~min}$ ). 


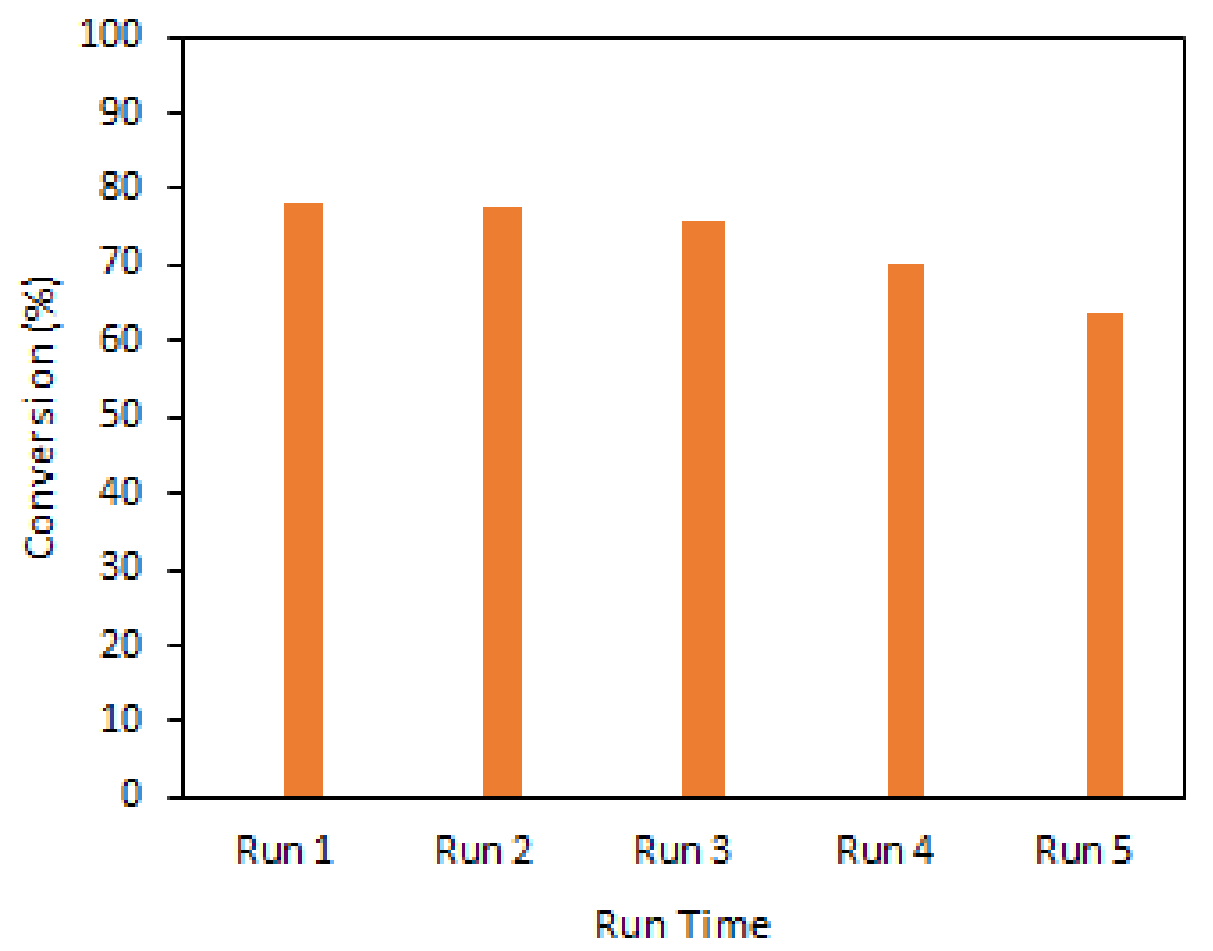

Fig. 10. Reusability of extractive-catalytic oxidative desulfurization of diesel fuel without any treatment after each run (oxidizer, $50 \mathrm{wt} . \% \mathrm{H}_{2} \mathrm{O}_{2}$, mole ratio of oxidizer to oxidized agent, acetonitrile as a extractor solvent, solvent to oil volume ratio $=1: 6$, temperature $70{ }^{\circ} \mathrm{C}$, catalyst dosage , $7.5 \mathrm{~g} / \mathrm{L}$, time: $30 \mathrm{~min}$ ). 
(a)

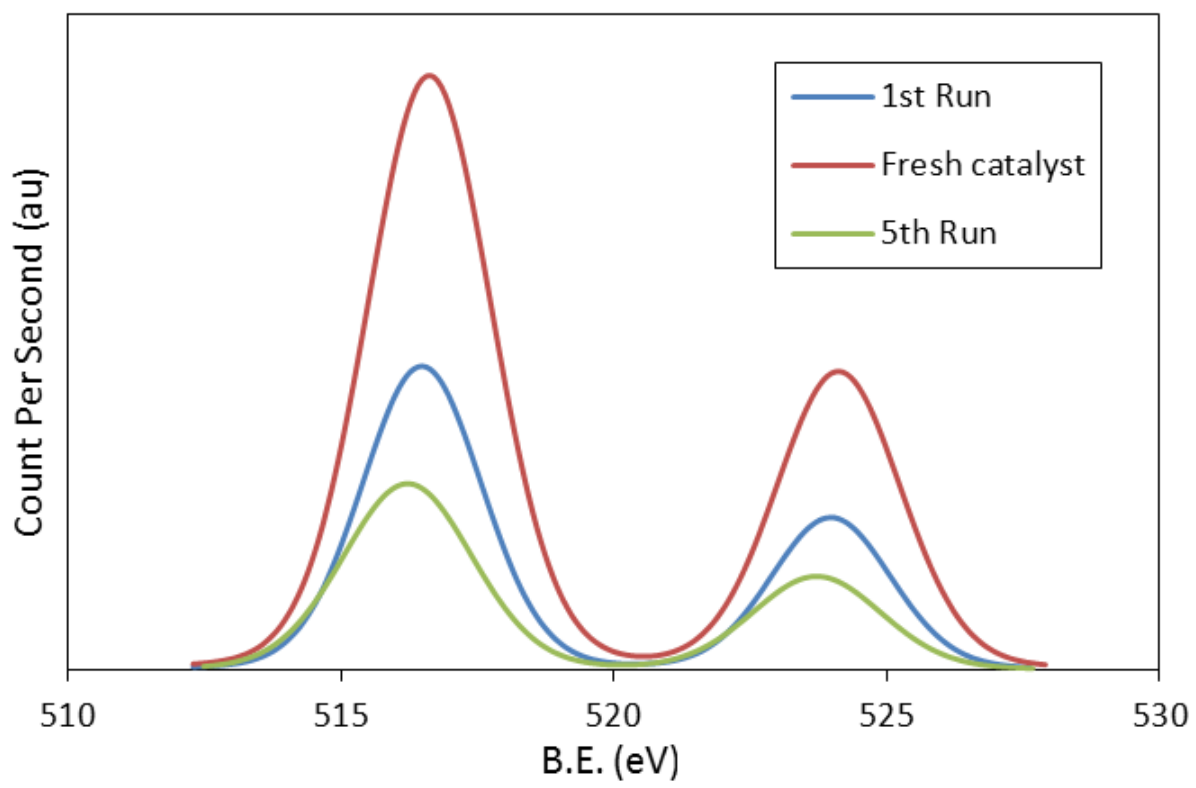

(b)

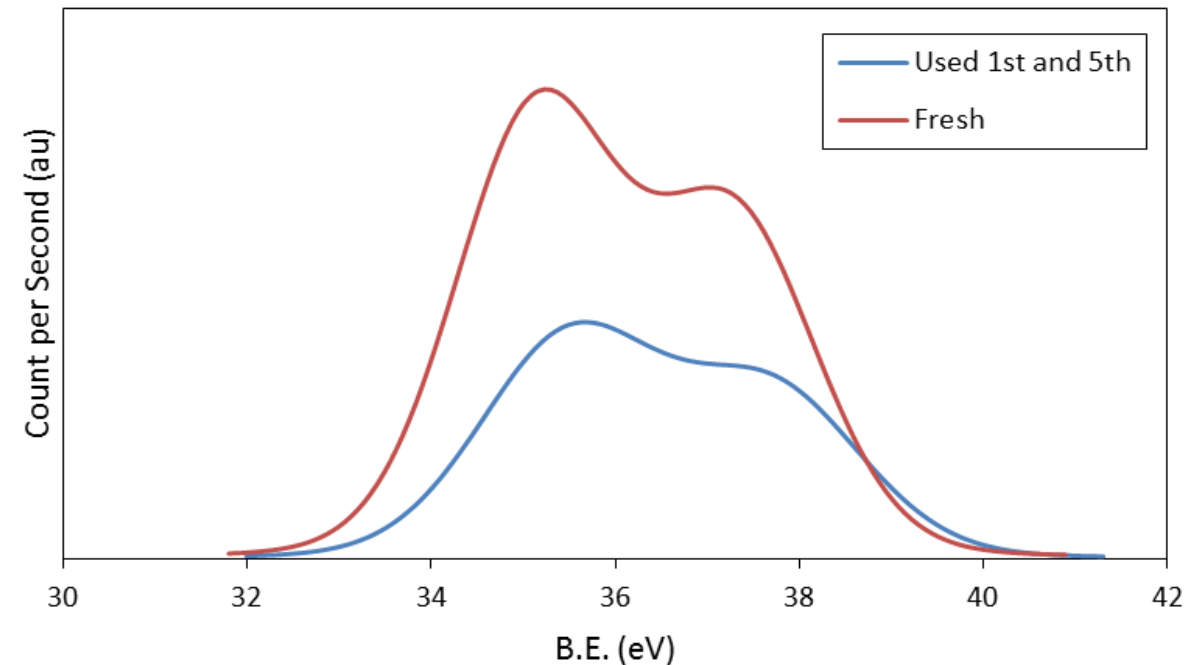

Fig. 11. XPS spectra of (a) V2p of fresh catalyst and after $1^{\text {st }}$ and $5^{\text {th }}$ runs and (b) W4f of fresh catalyst and after $1^{\text {st }}$ and $5^{\text {th }}$ runs. 